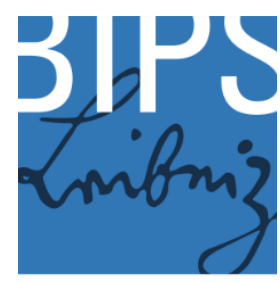

Leibniz Institute

for Prevention Research and

Epidemiology-BIPS

\title{
Associations between early body mass index trajectories and later metabolic risk factors in European children: The IDEFICS study
}

Claudia Börnhorst, Kate Tilling, Paola Russo, Yiannis Kourides, Nathalie Michels, Dénes Molnar, Gerardo Rodríguez, Luis A.Moreno, Vittorio Krogh, Yoav Ben-Shlomo, Wolfgang Ahrens, Iris Pigeot, on behalf of the IDEFICS consortium

\section{DOI}

10.1007/s10654-015-0080-z

\section{Published in}

European Journal of Epidemiology

\section{Document version}

Accepted manuscript

This is the author's final accepted version. There may be differences between this version and the published version. You are advised to consult the publisher's version if you wish to cite from it.

\section{Online publication date}

22 August 2015

\section{Corresponding author}

Claudia Börnhorst

\section{Citation}

Börnhorst C, Tilling K, Russo P, Kourides Y, Michels N, Molnar D, et al. Associations between early body mass index trajectories and later metabolic risk factors in European children: The IDEFICS study. Eur J Epidemiol. 2016;31(5):513-25.

This is a post-peer-review, pre-copyedit version of an article published in the European Journal of Epidemiology. The final authenticated version is available online at: http://dx.doi.org/10.1007/s10654-015-0080-z. 


\section{Associations between early body mass index trajectories and later metabolic risk factors in European children: The IDEFICS Study}

Börnhorst $\mathrm{C}^{1}$, Tilling $\mathrm{K}^{2}$, Russo $\mathrm{P}^{3}$, Kourides $\mathrm{Y}^{4}$, Michels $\mathrm{N}^{5}$, Molnár $\mathrm{D}^{6}$, Rodríguez $G^{7,8}$, Moreno $L^{7}$, Krogh $V^{9}$, Ben-Shlomo $Y^{2}$, Ahrens $W^{1,10}$, Pigeot $I^{1,10}$ on behalf of the IDEFICS consortium

${ }^{1}$ Leibniz Institute for Prevention Research and Epidemiology - BIPS, Bremen, Germany

${ }^{2}$ School of Social and Community Medicine, University of Bristol, Bristol, United Kingdom

${ }^{3}$ Institute of Food Sciences, National Research Council, Avellino, Italy

${ }^{4}$ Department of Chronic Diseases, National Institute for Health Development, Tallinn, Estonia

${ }^{5}$ Department of Public Health, Ghent University, Ghent, Belgium

${ }^{6}$ Department of Pediatrics, University of Pécs, Pécs, Hungary

${ }^{7}$ GENUD (Growth, Exercise, Nutrition and Development) Research Group, Faculty of Health Sciences, University of Zaragoza, Zaragoza, Spain

${ }^{8}$ IIS Aragón (Aragon Health Research Institute), Spain

${ }^{9}$ Department of Preventive and Predictive Medicine, Fondazione IRCCS Istituto Nazionale dei Tumori, Milan, Italy

${ }^{10}$ Institute of Statistics, Faculty of Mathematics and Computer Science, University of Bremen,

Bremen, Germany

Corresponding author:

Dr. rer. nat. Claudia Börnhorst

Leibniz Institute for Prevention Research and Epidemiology - BIPS,

Achterstr. 30,

28359 Bremen

Germany

Email: boern@bips.uni-bremen.de

Phone: +49-421-218-56946

Key words: IDEFICS study, childhood BMI growth, metabolic risk score, linear-spline mixed-effects model, data reduction 


\section{Abstract}

Background: Faster growth seems to be a common factor in several hypotheses relating early life exposures to subsequent health. This study aims to investigate the association between body mass index (BMI) trajectories during infancy/childhood and later metabolic risk in order to identify sensitive periods of growth affecting health.

Methods: In a first step, BMI trajectories of 3301 European children that participated in the multi-centre IDEFICS (Identification and Prevention of Dietary and Lifestyleinduced Health Effects in Children and Infants) study were modelled using linearspline mixed-effects models. The estimated random coefficients indicating initial subject-specific BMl and rates of change in BMl over time were used as exposure variables in a second step and related to a metabolic syndrome (MetS) score and its single components based on conditional regression models (mean age at outcome assessment: $8.5 \mathrm{yrs}$ ).

Results: All exposures under investigation, i.e. $\mathrm{BMI}$ at birth, rates of $\mathrm{BMI}$ change during infancy ( 0 to $<9 \mathrm{mths}$ ), early childhood ( $9 \mathrm{mths}$ to $<6 \mathrm{yrs}$ ) and later childhood ( $\geq 6 \mathrm{yrs}$ ) as well as current BMI z-score were significantly associated with the later MetS score. Associations were strongest for the rate of BMI change in early childhood (1.78 [1.66; 1.90]; $\beta$ estimate and $99 \%$ confidence interval) and current BMI z-score $(1.16[0.96 ; 1.38])$ and less pronounced for BMI at birth $(0.62$ [0.47; $0.78])$. Results slightly differed with regard to the single metabolic factors.

Conclusions: Starting from birth rapid BMI growth, especially in the time window of 9 $m$ ths to $<6 \mathrm{yrs}$, is significantly related to later metabolic risk in children. Much of the associations of early BMI growth may further be mediated through the effects on subsequent BMl growth. 


\section{Introduction}

The foetal origins hypothesis suggests that foetal malnutrition and subsequent low birth size or weight in conjunction with compensatory rapid growth increases the risk of chronic diseases in adulthood [1-3]. Also early postnatal nutrition has been proposed to have long-term health effects e.g. by promoting growth acceleration [4, 5]. The common denominator of several hypotheses relating early life exposures to later health seems to be faster growth during infancy and childhood [4]. To date, various associations between childhood trajectories of growth, including height, weight or body mass index (BMI), and later outcomes such as non-alcoholic fatty liver disease [6], asthma [7], hypertension [8-10], coronary heart disease [11, 12] and other cardiovascular (metabolic) risk factors [13-15] have been reported. With regard to BMI development during childhood, also the magnitude and timing of the infancy peak and adiposity rebound were suggested to be related to later obesity and metabolic factors [16-18]. Childhood obesity leads to alterations in metabolic parameters which may subsequently increase the risk for adverse cardiovascular outcomes, including the metabolic syndrome (MetS)[19]. The prevalence of the MetS was shown to increase with severity of obesity already in children and adolescents $[19,20]$. But still, the relative importance of adiposity status at time of outcome assessment compared to length/weight/BMI at birth or the trajectory of growth remains uncertain. Also little is known on sensitive time windows in infancy and childhood during which the later metabolic risk may be affected.

Therefore, this longitudinal study aims to investigate the associations of BMI trajectories during infancy/childhood and current BMI with a metabolic risk score and its single components (blood pressure, dyslipidaemia, central fat and insulin resistance) in a large cohort of European children. Focus will be put on the different periods of BMI growth (infancy, early childhood, later childhood) applying linearspline mixed effects models [21] in order to identify sensitive time windows during which growth may have a stronger effect on the later metabolic risk.

\section{Study population and methods}

The IDEFICS (Identification and Prevention of Dietary- and Lifestyle-Induced Health Effects in Children and Infants) cohort is a multi-centre population-based study aiming to investigate and prevent the causes of diet- and lifestyle-related diseases in 2- to 9-year-old children. The baseline survey (T0) was conducted from September 2007 to May 2008 in eight European countries (Sweden, Germany, Hungary, Italy, Cyprus, Spain, Belgium, Estonia). In total, 16228 children participated and fulfilled the inclusion criteria of the IDEFICS study. Children were approached via schools and kindergartens to facilitate equal enrolment of all social groups. The survey included interviews with parents concerning lifestyle habits and dietary intakes as well as physical examinations of the children. All measurements were taken using standardised procedures in all eight countries. Details on the design and objectives of the study can be obtained from Ahrens et al. [22, 23]. A follow-up survey (T1) was conducted in 2009/2010 applying the same standardised assessments where 13596 
children were enrolled (2555 newcomers; 11041 children who had participated in TO).

\section{Anthropometric measurements}

Height [cm] of the children was measured to the nearest $0.1 \mathrm{~cm}$ with a calibrated stadiometer (Seca 225 stadiometer, Birmingham, UK), body weight [kg] was measured in fasting state in light underwear on a calibrated scale and recorded to the nearest $0.1 \mathrm{~kg}$ (Tanita BC 420 SMA, Tanita Europe GmbH, Sindelfingen, Germany). $\mathrm{BMI}$ was calculated as weight $[\mathrm{kg}]$ divided by squared height $[\mathrm{m}]$. The $\mathrm{BMI}$ at last measurement ("current" BMl; measured at follow-up or, if missing due to loss to follow-up, T0 measurement) was converted to an age- and sex-specific z-score using the extended IOTF criteria [24]. Waist circumference [cm] was measured in upright position with relaxed abdomen and feet together, midway between the lowest rib margin and the iliac crest to the nearest $0.1 \mathrm{~cm}$ (elastic tape: Seca 200). Apart from the height and weight measured during the T0 and T1 survey, historical records of routine child visits including up to 35 additional height/weight measurements throughout childhood were abstracted in Italy, Cyprus, Belgium, Germany, Hungary, Spain and linked to the survey data. Information was supplemented by parentally reported birth weights and lengths in case measurements of birth length/weight were not available in the records of routine child visits.

\section{Blood pressure}

Blood pressure [mmHg] was measured with an automated oscillometric device (Welch Allyn 4200B-E2, Welch Allyn Inc. NY, USA) where the cuff length was chosen depending on the child's arm circumference. After at least 5 minutes of resting in a sitting position, two measurements were taken with two minutes interval in between, plus a third one in case the first and second measurements differed by $>5 \%$. The average of the two (or three) measurements was used in the subsequent analysis.

\section{Blood collection}

Fasting blood was collected either by venipuncture or by capillary sampling as described in detail in Ahrens et al. [25]. To ensure that basic data on metabolic disorders were available for as many children as possible a point-of-care analyser (Cholestech LDX, Cholestech Corp.) was used to assess blood glucose, high-density lipoprotein $(\mathrm{HDL})$ and low-density lipoprotein (LDL) cholesterol and triglycerides. Blood samples were analysed centrally in a laboratory accredited by the International Organization for Standardization 15189 using a luminescence immunoassay (AUTOGA Immulite 2000, Siemens, Eschborn, Germany) for insulin $[\mu \mathrm{IU} / \mathrm{ml}]$. The homeostasis model assessment (HOMA) [26] was used as measure of insulin resistance where HOMA was calculated as fasting insulin $(\mu \mathrm{lU} / \mathrm{ml}) \times$ fasting glucose $(\mathrm{mmol} / \mathrm{l}) / 22.5$. 
As levels of many health parameters change during childhood, a new score of cardiometabolic risk has been proposed by Ahrens et al. [25]. This score is constructed applying a z-score standardisation to the four MetS components using recently published reference values for young children [27-29]. Measures for (1) hypertension (blood pressure; BP), (2) dyslipidaemia (lipid levels; LIPID), (3) central fat (waist circumference; WAIST) and (4) insulin resistance (HOMA index; HOMA) are combined into one continuous variable where a higher score suggests a higher metabolic risk. For the BP z-score, the mean of the height-, age- and sex-specific zscores of diastolic and systolic blood pressure was calculated. For the LIPID z-score the mean of the sex- and age-specific z-scores of triglycerides and HDL was used where the latter was multiplied with -1 due to the inverse association with the metabolic risk. The MetS score is calculated as the sum of the four z-scores representing the four MetS components:

MetS score = BP z-score + LIPID z-score + WAIST z-score + HOMA z-score.

In general, the last available measurements were used for the MetS score calculation.

\section{Covariate information}

Information on age (yrs), sex, country, pre-term delivery (yes vs. no), breast feeding duration (mths), highest educational level of parents according to the International Standard Classification of Education (ISCED), consumption frequency of junk food (times/week; sum of five food frequency questionnaire variables for consumption of sweetened drinks, chocolate, candy bars, candies, crisps, corn crisps, popcorn, chocolate-based spreads, etc), consumption frequency of fruits and vegetables (times/week; sum of five variables for fruit and vegetable consumption excluding potatoes) was obtained from proxy-reported questionnaires collected during the baseline and follow-up survey. Free-living physical activity was objectively measured using Actigraph uniaxial accelerometers (either ActiTrainer or GT1M; Actigraph, LLC, Pensacola, FL, USA) where minutes per day spent in moderate-to-vigorous physical activity (MVPA) were calculated to adjust for physical activity. Covariates to be included in the models relating BMI growth to the outcome variables were selected a priori according to existing knowledge.

Analysis dataset

The flow chart in Figure 1 illustrates the number of height/weight measurements available from the different sources and summarises the exclusion process leading to the final analysis dataset. In total, 60647 height/weight measurements of 12700 children from the six countries that collected records from routine child visits were available. The time points and numbers of measurements per child differed. Implausible height/weight measurements (1666 values above/below age- and sexspecific mean +/- 4 SD, 30 duplicates) and BMI values (597 values above/below 
mean +8 or $-4 \mathrm{SD}$ ) were excluded. To account for collinearity of measurements taken closely in time, a minimum time lag of $1 \mathrm{mth}$ (for measurement taken below $6 \mathrm{mths}$ of age), 2 mths (measurement between 6 mths to $1.5 \mathrm{yrs}$ ) or $3 \mathrm{mths}$ (measurements > $1.5 \mathrm{yrs}$ ), respectively, was imposed by random deletion of 6794 measurements taken closer in time. The final dataset included only children with a minimum of 4 measurements on height and weight and information on delivery status (full-term vs. pre-term) leading to a final analysis dataset of 29418 height/weight measurements from 3301 children for the growth model. Online resource A1 displays the number of children with $4,5,6$, etc. available BMI measurements.

Out of these 3301 children, 2264 provided the full set of variables required to calculate the MetS score and its components ( $\mathrm{T} 1$ values used in 1187 children; T0 values used in 1077 children) out of which 1381 had full covariate information.

\section{Statistical analysis}

\section{Step 1: Selection and estimation of a growth model for BMI}

Children's BMI trajectories were modelled using linear-spline mixed-effects models with two levels (measurement occasion and individual) allowing individuals to have different intercepts and slopes, i.e. their own trajectory [21]. These models can easily handle unbalanced data with a different number of measurements per child assessed at different points in time. Moreover, such models allow for change in scale and variance of BMl over time.

In a first step, all combinations of fractional polynomials with up to three powers of age out of the following powers $(-2,-1,-0.5$, log, square root, $1,2,3)$ were estimated to get an indication on the best knot point positions. The best fitting model was a fractional polynomial with the following three powers: age ${ }^{1}$, age $^{2}$, log(age) (model selection criteria: AIC). Based on visual inspection of this polynomial as well as based on literature [30-33], two knot points for the linear-spline models were selected at $9 \mathrm{mths}$ and 6 yrs to account for the average ages at infancy peak and adiposity rebound. Accordingly, starting with BMI at birth, three periods of growth were modelled: 0 to $9 \mathrm{mths}$ (S1: infancy), 9 mths to $6 \mathrm{yrs}$ (S2: early childhood) and $\geq 6 \mathrm{yrs}$ (S3; later childhood).

The growth model was adjusted for sex and delivery status (pre-term vs. full-term) including interactions with the different splines, as well as for measured vs. reported birth heights/weights (binary indicator). A formal description of the linear-spline growth model is given in the online resource A2.

The model was estimated stratified by age group (aged $2-<6$ yrs at last measurement vs $\geq 6$ yrs at last measurement). In the younger age group, the spline for the third period (S3; indicating period $\geq 6 \mathrm{yrs}$ ) was not added to the model as these children obviously did not have measurements for this period. Models were checked for residual confounding by plotting the occasion-level residuals against age and height. Only minor differences comparing the distributions of residuals for lower/higher heights and ages were observed such that there was no evidence of residual confounding. 
The main purpose of step 1 was to reduce the dimensionality of the data and to derive exposure measures that are comparable between study subjects despite the differing ages at height/weight measurements and differing numbers of measurements.

Step 2: Estimation of associations between BMI trajectories and MetS score and its components

In the second step, the random intercepts and slopes estimated in the growth model in step 1 were related to the MetS score and its components. These random subjectspecific coefficients indicate the deviations for child $i$ from the average intercept (BMI at birth) as well as from the average velocities (slopes) of BMI growth between 0 to 9 mths, 9 mths to 6 yrs and $\geq 6$ yrs (the latter only for children being $\geq 6$ yrs at last measurement). The random coefficients were standardised to achieve comparability of model estimates in the different periods and were then used as exposure variables. Conditional linear regression models [34] were applied to estimate the total effects (meaning the sum of direct and indirect effects) of BMI at birth, the rates of change in the different growth periods $(\mathrm{S} 1, \mathrm{~S} 2, \mathrm{~S} 3)$ as well as current BMl z-score calculated according to the extended IOTF criteria [24] on the five outcomes (MetS score, BP z-score, LIPID z-score, WAIST z-score, HOMA z-score) adjusting for continuous age, sex, country and previous but not subsequent measurements of BMI growth (models with basic adjustment; $\mathrm{N}=2264$ ). For instance when analysing the association between rate of $\mathrm{BMI}$ change in period $\mathrm{S} 2$ and an outcome, the model was adjusted for BMI at birth and rate of BMI change in S1 but not in S3. All models were analysed stratified by age group ( $<6 \mathrm{vs}$. $\geq 6 \mathrm{yrs}$ ) and also by age group and sex (not adjusting for sex in the latter case).

All models were fitted again additionally adjusting for confounders occurring at the same time or prior to the exposure, i.e. maximum ISCED level of parents was added to all models. Breast feeding duration (mths) was added to all models except those for BMI at birth. Junk food frequency (times/week), fruit and vegetable frequency (times/week) and minutes per day spent in MVPA were added to models for the last periods of growth (S2 for $<6 \mathrm{yr}$ olds, S3 for $\geq 6 \mathrm{yr}$ olds) and for current BMl z-score (models with full adjustment; $\mathrm{N}=1381$ ). The latter models were additionally adjusted for current height when BP z-score was the outcome of interest. Again models were analysed stratified by age group ( $<6 \mathrm{vs}$. $\geq 6 \mathrm{yrs}$ ) but not by sex as the sample sizes became too small to achieve stable model estimates. In a sensitivity analysis, all models were run stratified for children delivered full-term vs. pre-term. $99 \%$ confidence intervals $(\mathrm{Cl})$ were used (rather than the more usual $95 \%$ ) to account at least partially for multiple testing. All analyses were performed using $\mathrm{SAS}^{\circledR}$ statistical software version 9.3 (SAS Institute, Inc., Cary, NC). 


\section{Results}

208 A description of the study populations with basic $(\mathrm{N}=2264)$ and full covariate information ( $\mathrm{N}=1381)$ including mean levels of the MetS score and its single components by age group is given in Table 1 . Both sexes were almost equally distributed (51.6\% [51.0\%] boys, 48.4\% [49\%] girls; basic sample [sample with covariate information in brackets]) whereas there was a much larger percentage of children in the older compared to the younger age group (83.7\% [87.6\%] vs. 16.3\% [12.4\%]). The mean MetS score was slightly higher in older children (0.5 [0.5] vs. 0.1 higher in the older children except for mean triglyceride levels in the basic sample. In general, there were only minor differences comparing age, sex, and outcome variables between the study samples with basic and full covariate information.

\section{(please insert Table 1 here)}

Results of the BMI growth model (step 1) are presented in online resources A3 and A4. Associations between the random intercepts and slopes estimated based on the BMl growth model and the metabolic outcomes (step 2) are presented in Table 2 (basic adjustment) and Table 3 (full adjustment). These effect estimates give the total effects of the exposures on the outcome, meaning the sum of the direct and indirect effects on the outcome. All exposures under investigation, i.e. BMl at birth, rates of BMI change during infancy (S1), early (S2) and later childhood (S3) as well as current BMI Z-score were positively associated with the later MetS score. Associations were strongest for the rate of BMI change in S2 and current BMI Zscore and least pronounced for BMI at birth and the rate of BMI change in S1 (see Table 2). For instance, the change in the MetS score associated with a one standard deviation increase in the rate of BMI change was 1.78 in period S2 but only 0.29 and 1.06 in periods S1 and S3, respectively (model for $\geq 6 \mathrm{yr}$ olds). The BP z-score was not related to $\mathrm{BMI}$ at birth and rate of BMI change during $\mathrm{S} 1$ in $<6 \mathrm{yr}$ olds, but positively associated with BMI at birth and rates of BMI change during $\mathrm{S} 1, \mathrm{~S} 2, \mathrm{~S} 3$ and current BMI z-score in the older age group where associations were largest for exposures closer in time and larger in boys compared to girls. There was evidence of a positive association between HOMA z-score and rates of BMI change during S2, S3 as well as with current BMI z-score where associations were strongest during S2. For LIPID z-score, no association with BMI at birth, rate of BMI change during S3 or with current BMI z-score was found but rates of BMI change during S1 and S2 were positively associated with the LIPID z-score in the older age group (both in boys and girls). No such association was found in the younger age group. All exposures exhibited significant positive associations with the WAIST z-score, with strongest associations for rates of BMI change in $\mathrm{S} 2$ as well as for current BMI Z-score. Of all the individual MetS components, associations were strongest with the WAIST zscore.

After adjustment for additional covariates (Table 3), estimates changed only slightly, in general. In $<6 \mathrm{yr}$ olds, the estimate of the association of current BMI with blood 
pressure was slightly attenuated, with a wider confidence interval. When comparing the results for children delivered full-term vs. pre-term (sensitivity analysis; see online resource A5), no marked differences in the effect estimates were observed for any of the outcomes in the older age group and only small differences in the younger age group considering the reduced sample size in the pre-term delivery group.

(please insert Table 2 and 3 here)

\section{Discussion}

In this study, sophisticated statistical models were applied to investigate rates of BMI change during childhood in relation to later metabolic risk. Greater BMI growth in all periods under investigation was found to be related to a higher MetS score conditional on previous BMI growth, BMI at birth and confounding factors and hence seems to have adverse long-term effects on cardio-metabolic outcomes. The strongest association was observed for the period of $9 \mathrm{mths}$ to $6 \mathrm{yrs}$ where the BMI growth velocity is typically negative, i.e. BMI is expected to decrease. However, the underlying mechanism is not completely understood yet and cannot be determined based on the data at hand such that its investigation remains a task for future research. Our results are in line with the "growth acceleration hypothesis" which suggests rapid growth, especially during infancy but also during childhood, to program the metabolic profile such that it becomes susceptible to obesity and other components of metabolic syndrome [4].

Direct comparison with other studies is hampered by the limited number of studies relating BMI growth to metabolic risk, but also due to the differences in statistical methods applied, differences in ages at exposure/outcome assessment, choices of outcome/exposure variables and differing study populations. This should be kept in mind when comparing our results with previous research publications.

Ekelund et al. [35] recently reported positive associations between infancy weight gain ( 0 to 6 mths) and a continuous metabolic risk score at age 17 in 128 adolescents where the association was not observed in early childhood (3-6 yrs). In another small study by Leunissen et al. [36] rapid weight gain from 0 to 3 mths was found to be associated with several cardio-metabolic risk factors in early adulthood (18-24 yrs). Later periods of weight gain were not addressed in that study. Applying linear-spline mixed effects models, Howe et al. [13] assessed associations between ponderal index $(\mathrm{PI})$ (0-2 yrs) and BMI trajectories (2-10 yrs) during childhood and several cardiovascular risk factors measured at age 15 in a UK cohort. BMI changes in childhood, especially in later childhood, were found to be predictive for most cardiovascular risk factors in adolescents but changes in PI during early infancy were not. Depending on the age at outcome assessment the time window of BMI change having the largest association with the metabolic outcomes may vary which could explain these slightly differing results. Also in our study, some associations were only found in children aged $\geq 6$ yrs at outcome assessment, but not in the younger age group. However, this may partly result from the smaller study sample leading to 
reduced statistical power and hence to greater instability in the estimates such that the results in the younger age group must be interpreted with greater caution. Howe et al. [13] further suggested some associations between PI/BMI changes and cardiovascular risk factors being slightly stronger in boys compared to girls but also pointed to the lack of studies comparing effects of BMI changes on metabolic risk between sexes. In our study, stronger associations for boys compared to girls were only observed for blood pressure.

In the present analysis, BMI at birth was unrelated to later blood pressure in the younger age group and slightly positively related to blood pressure in the older age group. As discussed in a recent review [37], several papers report negative associations between birth weight and blood pressure, but the reported effects are often (wrongly) adjusted for current weight yielding misleading conclusions [38]. For this reason, we applied conditional regression models that were adjusted for previous but not subsequent BMI measurements to estimate the total (direct plus indirect) effects of the different exposures on the outcome. Consistently with our results, Tilling et al. [8] reported associations between faster weight gain in early childhood and blood pressure at age 6.5 but no association between birth weight and blood pressure, applying similar statistical methods. Menezes et al. [39] observed birth length to be positively related to blood pressure in early adolescence, but neither birth weight nor ponderal index. So part of the inconsistent results may be due to the use of different measures for growth status at birth. However, in one large study [40] $(\mathrm{N}=25874)$ the negative association between birth weight and later blood pressure was reported to increase with age supporting the recently debated 'amplification' hypothesis [41]. Hence, another explanation of the differing results might be that the age at outcome assessment in our study was too small.

In a study by Gardner et al. [42], cross-sectional and longitudinal associations between different measures of obesity at 5 years and insulin resistance (at age 5 and later ages) were investigated where longitudinal associations were much stronger compared to cross-sectional associations. Consistently, we observed stronger associations of the rate of BMI change between 9 mths and 6 yrs with later HOMA zscore compared to the associations of BMI change in the third period ( $\geq 6 \mathrm{yrs}$ ) and of current BMI (adjusting for previous changes in BMI and BMI at birth) with HOMA zscore.

Only few studies investigated the long-term effects of BMI change or weight gain during infancy and childhood on later lipid levels, with inconsistent results [13, 35, 36]. Whether the significant associations of rates of BMI change between 0 to $9 \mathrm{mths}$ and $9 \mathrm{mths}$ to $6 \mathrm{yrs}$, but neither of BMI change in the third period ( $\geq 6 \mathrm{yrs}$ ) nor of current BMI with LIPID z-score actually result from time-delayed effects of BMI change on lipid levels needs to be further explored in future studies. Various studies showed rapid growth in infancy and childhood to be a predictor of overweight and obesity in later childhood, adolescence and adulthood [43, 44]. As waist circumference and BMI are typically highly correlated [45], the strong associations between rates of BMI change during infancy and childhood and later waist circumference were expected. In this context, we also reviewed the relations 
between our derived growth measures and BMI at outcome assessment. When adding current $\mathrm{BMI}$ to the models for $\mathrm{BMI}$ at birth and rate of $\mathrm{BMI}$ change between 0 to $9 \mathrm{mths}$ and $9 \mathrm{mths}$ to $6 \mathrm{yrs}$, associations were largely attenuated (data not shown). This suggests that the associations between BMI at birth and changes of BMI during childhood on later metabolic risk may be largely mediated by the later BMI status. This means that not only the direct effects of early BMI growth but also the indirect effects through its effects on future measurements may explain the associations with the later MetS score. Apart from these potentially mediated effects, there may be time-delayed effects, i.e. a time shift between the development of obesity and the development of metabolic comorbidities. Results of the Earlybird study indicated that most excess weight before puberty is gained prior to five years of age underpinning the need to start obesity interventions already early in life [46].

\section{Strengths and limitations}

In this study, heights/weights were obtained from different sources (health records, parentally reported birth weights/heights, measurements in IDEFICS study) and the number of measurements differed among children. Furthermore, growth measurements were not taken at the same ages and the age at outcome assessment differed among children. These common problems in large cohort studies were overcome by the use of linear spline mixed-effects models. However, these models assume a piecewise linear relationship between age and BMI and require the selection of knot points. Timing and magnitude of infancy peak and adiposity rebound vary between children and have been suggested to be associated with later obesity, blood pressure and metabolic risk [16-18, 30-32]. However, as the ages of infancy peak and adiposity rebound are in general unknown for a single child, from a public health perspective it would be more important to identify time windows in childhood during which interventions are most promising. For this reason, we did not model the association between timing or magnitude of adiposity rebound or infancy peak and metabolic factors but focussed on the rates of BMI change ("BMI growth") in different time windows and their associations with later health risks. A further subdivision, especially of the time window of 9 mths to $6 \mathrm{yrs}$, into smaller periods of growth would have been desirable to better approximate the BMI trajectory, but would have required a larger number of repeated measurements for each subject. To estimate a growth model through infancy and childhood, the BMI was used as single measure for adiposity. This on the one hand eased interpretation but on the other hand complicated comparisons with previous studies that often used the ponderal index for birth or early infancy. Although non-linear models (e.g. fractional polynomial models) may result in a better approximation of growth in relation to age, associations between respective model estimates and an outcome are not clinically relevant [14]. The linear-spline model is a compromise between precision of growth modelling and interpretable estimates of BMI trajectories. They further reduce the dimensionality of data and hence the collinearity problem and may even reduce measurement error that could occur when trying to group exposures to common ages [34]. However, it should be noted that it does not take the uncertainty 
in the estimates of BMI at birth and rates of BMI change in step 1 into account, so standard errors may be underestimated [47]. A recent paper by Sayers et al. [47] showed in a simulation study that the 2-step model provides consistent conditional estimates when linearly relating all exposures to an outcome but reported biased estimates for unconditional associations where the magnitude of the bias depends on the measurement error in the repeated measurements. Multivariate growth models (joint models) were suggested to solve this issue $[47,48]$ and may be a promising field for future investigations.

The IDEFICS survey was conducted setting-based and not intended to provide nationally representative samples. Although this approach enabled equal enrolment of all social groups, non-response bias resulting from over-representation of certain subgroups cannot be precluded where in particular socio-economic status is a key factor associated with participation as well as with health outcomes. In the present study, attrition effects, that are often observed in cohort studies, should play a minor role as participation in T0 and T1 was not a requirement for inclusion. The sophisticated statistical methodology, the longitudinal study design, the large number of repeated measurements in a European dataset of young children, the standardised covariate assessment and detailed assessment of disease risk using a continuous MetS score based on newly derived reference values are further strengths of this study.

\section{Conclusions}

Sophisticated statistical models were applied to investigate BMI growth during infancy and childhood in relation to later metabolic risk measured based on a continuous MetS score. Higher BMI growth during all periods under investigation, especially in the period from $9 \mathrm{mths}$ to $6 \mathrm{yrs}$, was related to a higher metabolic risk independent of prior BMI growth, BMI at birth and confounding factors. BMI growth in early periods may not only directly be associated with metabolic factors, but also indirectly through its impact on later BMI status.

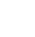

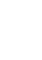




\section{Contributor's Statement}

420

421

422

423

424

425
This manuscript represents original work that has not been published previously and is currently not considered by another journal. Each author has seen and approved the contents of the submitted manuscript. All authors contributed to conception and design, acquisition of data, analysis or interpretation of data.

\section{Funding}

This work was supported by the European Community and was funded within the Sixth RTD Framework Programme [Contract No. 016181 (FOOD)].

\section{Acknowledgements}

This work was done as part of the IDEFICS study (www.idefics.eu). We gratefully acknowledge the financial support of the European Community. The authors wish to thank the IDEFICS children and their parents for participating in the extensive examination procedures involved in this study. We are grateful for the support by school boards, headmasters and communities.

\section{Statement of Ethics and Informed Consent}

We certify that all applicable institutional and governmental regulations concerning the ethical use of human volunteers were followed during this research. Approval by the appropriate Ethics Committees was obtained by each centre doing the fieldwork. Study children did not undergo any procedures unless both they and their parents had given consent for examinations, collection of samples, subsequent analysis and storage of personal data and collected samples. Study subjects and their parents could consent to single components of the study while abstaining from others.

All procedures were in accordance with the ethical standards of the institutional and/or national research committee and with the 1964 Helsinki declaration and its later amendments or comparable ethical standards.

\section{Conflict of Interest}

None declared. 
1. $\quad$ Barker DJ. In utero programming of chronic disease. Clin Sci (Lond) 1998; 95: 115-128.

2. $\quad$ Barker DJ. A new model for the origins of chronic disease. Med Health Care Philos 2001; 4: 31-35.

3. Barker DJ. The developmental origins of adult disease. J Am Coll Nutr 2004; 23: 588-595.

4. Singhal A, Lucas A. Early origins of cardiovascular disease: is there a unifying hypothesis? Lancet 2004; 363: 1642-1645.

5. Lucas A. Long-term programming effects of early nutrition -- implications for the preterm infant. J Perinatol 2005; 25 Suppl 2: S2-6.

6. Anderson EL, Howe LD, Fraser A, Callaway MP, Sattar N, Day C, Tilling K, Lawlor DA. Weight trajectories through infancy and childhood and risk of non-alcoholic fatty liver disease in adolescence: The ALSPAC study. Journal of Hepatology 2014; 61: 626-632.

7. Anderson EL, Fraser A, Martin RM, Kramer MS, Oken E, Patel R, Tilling K. Associations of postnatal growth with asthma and atopy: the PROBIT Study. Pediatr.Allergy Immunol. 2013; 24: 122130.

8. Tilling K, Davies N, Windmeijer F, Kramer MS, Bogdanovich N, Matush L, Patel R, Smith GD, Ben-Shlomo Y, Martin RM. Is infant weight associated with childhood blood pressure? Analysis of the Promotion of Breastfeeding Intervention Trial (PROBIT) cohort. Int J Epidemiol 2011; 40: 1227-1237. 9. Wills AK, Lawlor DA, Matthews FE, Sayer AA, Bakra E, Ben-Shlomo Y, Benzeval M, Brunner E, Cooper R, Kivimaki M, Kuh D, Muniz-Terrera G, Hardy R. Life course trajectories of systolic blood pressure using longitudinal data from eight UK cohorts. PLoS Med 2011; 8: e1000440.

10. Barker DJ. The fetal origins of hypertension. J Hypertens Suppl 1996; 14: S117-120.

11. Barker DJ. Fetal origins of coronary heart disease. BMJ 1995; 311: 171-174.

12. Barker DJ. Coronary heart disease: a disorder of growth. Horm Res 2003; 59 Suppl 1: 35-41.

13. Howe LD, Tilling K, Benfield L, Logue J, Sattar N, Ness AR, Smith GD, Lawlor DA. Changes in ponderal index and body mass index across childhood and their associations with fat mass and cardiovascular risk factors at age 15. PLoS One 2010; 5: e15186.

14. Tilling K, Davies NM, Nicoli E, Ben-Shlomo Y, Kramer MS, Patel R, Oken E, Martin RM. Associations of growth trajectories in infancy and early childhood with later childhood outcomes. Am J Clin Nutr 2011; 94: 1808-1813.

15. Barker DJ. Fetal nutrition and cardiovascular disease in later life. Br Med Bull 1997; 53: 96108.

16. Cole TJ. Children grow and horses race: is the adiposity rebound a critical period for later obesity? BMC Pediatr 2004; 4: 6.

17. Gonzalez L, Corvalan C, Pereira A, Kain J, Garmendia ML, Uauy R. Early adiposity rebound is associated with metabolic risk in 7-year-old children. Int J Obes (Lond) 2014; 38: 1299-1304.

18. Hof MH, Vrijkotte TG, de Hoog ML, van Eijsden M, Zwinderman AH. Association between infancy BMI peak and body composition and blood pressure at age 5-6 years. PLoS One 2013; 8: e80517.

19. Weiss R, Caprio S. The metabolic consequences of childhood obesity. Best Pract Res Clin Endocrinol Metab 2005; 19: 405-419.

20. Weiss R, Dziura J, Burgert TS, Tamborlane WV, Taksali SE, Yeckel CW, Allen K, Lopes M, Savoye M, Morrison J, Sherwin RS, Caprio S. Obesity and the metabolic syndrome in children and adolescents. N Engl J Med 2004; 350: 2362-2374.

21. Howe LD, Tilling K, Matijasevich A, Petherick ES, Santos AC, Fairley L, Wright J, Santos IS, Barros AJ, Martin RM, Kramer MS, Bogdanovich N, Matush L, Barros H, Lawlor DA. Linear spline multilevel models for summarising childhood growth trajectories: A guide to their application using examples from five birth cohorts. Stat Methods Med Res 2013.

22. Ahrens W, Bammann K, de Henauw S, Halford J, Palou A, Pigeot I, Siani A, Sjostrom M. Understanding and preventing childhood obesity and related disorders--IDEFICS: a European multilevel epidemiological approach. Nutr.Metab Cardiovasc.Dis. 2006; 16: 302-308.

23. Ahrens W, Bammann K, Siani A, Buchecker K, De Henauw S, lacoviello L, Hebestreit A, Krogh V, Lissner L, Marild S, Molnar D, Moreno LA, Pitsiladis YP, Reisch L, Tornaritis M, Veidebaum T, Pigeot 
I. The IDEFICS cohort: design, characteristics and participation in the baseline survey. Int.J.Obes.(Lond) 2011; 35 Suppl 1: S3-15.

24. Cole TJ, Lobstein T. Extended international (IOTF) body mass index cut-offs for thinness, overweight and obesity. Pediatr Obes 2012; 7: 284-294.

25. Ahrens W, Moreno LA, Marild S, Molnar D, Siani A, De Henauw S, Böhmann J, Günther K, Hadjigeorgiou C, lacoviello L, Lissner L, Veidebaum T, Pohlabeln H, Pigeot I. Metabolic syndrome in young children: definitions and results of the IDEFICS study. Int J Obes (Lond) 2014; 38 Suppl 2: S4-14. 26. Matthews DR, Hosker JP, Rudenski AS, Naylor BA, Treacher DF, Turner RC. Homeostasis model assessment: insulin resistance and beta-cell function from fasting plasma glucose and insulin concentrations in man. Diabetologia 1985; 28: 412-419.

27. Barba G, Buck C, Bammann K, Hadjigeorgiou C, Hebestreit A, Marild S, Molnar D, Russo P, Veidebaum T, Vyncke K, Ahrens W, Moreno LA. Blood pressure reference values for European nonoverweight school children: The IDEFICS study. Int J Obes (Lond) 2014; 38 Suppl 2: S48-56.

28. De Henauw S, Michels N, Vyncke $K$, Hebestreit A, Russo P, Intemann T, Peplies J, Fraterman A, Eiben $G$, de Lorgeril M, Tornaritis M, Molnar D, Veidebaum T, Ahrens W, Moreno LA. Blood lipids among young children in Europe: results from the European IDEFICS study. Int J Obes (Lond) 2014; 38 Suppl 2: S67-75.

29. Nagy P, Kovacs E, Moreno LA, Veidebaum T, Tornaritis M, Kourides $Y$, Siani A, Lauria F, Sioen I, Claessens M, Marild S, Lissner L, Bammann K, Intemann T, Buck C, Pigeot I, Ahrens W, Molnar D. Percentile reference values for anthropometric body composition indices in European children from the IDEFICS study. Int J Obes (Lond) 2014; 38 Suppl 2: S15-25.

30. Rolland-Cachera MF, Deheeger M, Bellisle F, Sempe M, Guilloud-Bataille M, Patois E. Adiposity rebound in children: a simple indicator for predicting obesity. Am J Clin Nutr 1984; 39: 129135.

31. Rolland-Cachera MF, Deheeger M, Maillot M, Bellisle F. Early adiposity rebound: causes and consequences for obesity in children and adults. Int J Obes (Lond) 2006; 30 Suppl 4: S11-17.

32. Silverwood RJ, De Stavola BL, Cole TJ, Leon DA. BMI peak in infancy as a predictor for later BMI in the Uppsala Family Study. Int J Obes (Lond) 2009; 33: 929-937.

33. Whitaker RC, Pepe MS, Wright JA, Seidel KD, Dietz WH. Early adiposity rebound and the risk of adult obesity. Pediatrics 1998; 101: E5.

34. Tu YK, Tilling K, Sterne JA, Gilthorpe MS. A critical evaluation of statistical approaches to examining the role of growth trajectories in the developmental origins of health and disease. Int $J$ Epidemiol 2013; 42: 1327-1339.

35. Ekelund U, Ong KK, Linne Y, Neovius M, Brage S, Dunger DB, Wareham NJ, Rossner S. Association of weight gain in infancy and early childhood with metabolic risk in young adults. J.Clin.Endocrinol.Metab 2007; 92: 98-103.

36. Leunissen RW, Kerkhof GF, Stijnen T, Hokken-Koelega A. Timing and tempo of first-year rapid growth in relation to cardiovascular and metabolic risk profile in early adulthood. JAMA 2009; 301: 2234-2242.

37. Huxley R, Neil A, Collins R. Unravelling the fetal origins hypothesis: is there really an inverse association between birthweight and subsequent blood pressure? Lancet 2002; 360: 659-665.

38. Tu YK, West R, Ellison GT, Gilthorpe MS. Why evidence for the fetal origins of adult disease might be a statistical artifact: the "reversal paradox" for the relation between birth weight and blood pressure in later life. Am J Epidemiol 2005; 161: 27-32.

39. Menezes AM, Hallal PC, Horta BL, Araujo CL, Vieira Mde F, Neutzling M, Barros FC, Victora CG. Size at birth and blood pressure in early adolescence: a prospective birth cohort study. $\mathrm{Am} J$ Epidemiol 2007; 165: 611-616.

40. Davies AA, Smith GD, May MT, Ben-Shlomo Y. Association between birth weight and blood pressure is robust, amplifies with age, and may be underestimated. Hypertension 2006; 48: 431-436.

41. Law CM, de Swiet M, Osmond C, Fayers PM, Barker DJ, Cruddas AM, Fall CH. Initiation of hypertension in utero and its amplification throughout life. BMJ 1993; 306: 24-27. 
42. Gardner DS, Metcalf BS, Hosking J, Jeffery AN, Voss LD, Wilkin TJ. Trends, associations and predictions of insulin resistance in prepubertal children (EarlyBird 29). Pediatr Diabetes 2008; 9: 214220.

43. Baird J, Fisher D, Lucas P, Kleijnen J, Roberts $\mathrm{H}$, Law $\mathrm{C}$. Being big or growing fast: systematic review of size and growth in infancy and later obesity. BMJ 2005; 331: 929.

44. Monteiro PO, Victora CG. Rapid growth in infancy and childhood and obesity in later life--a systematic review. Obes Rev 2005; 6: 143-154.

45. Brannsether B, Eide GE, Roelants M, Bjerknes R, Juliusson PB. Interrelationships between anthropometric variables and overweight in childhood and adolescence. Am J Hum Biol 2014; 26: 502-510.

46. Gardner DS, Hosking J, Metcalf BS, Jeffery AN, Voss LD, Wilkin TJ. Contribution of early weight gain to childhood overweight and metabolic health: a longitudinal study (EarlyBird 36). Pediatrics 2009; 123: e67-73.

47. Sayers A, Heron J, Smith A, Macdonald-Wallis C, Gilthorpe M, Steele F, Tilling K. Joint modelling compared with two stage methods for analysing longitudinal data and prospective outcomes: A simulation study of childhood growth and BP. Stat Methods Med Res 2014: [epub ahead of print].

48. Macdonald-Wallis C, Lawlor DA, Palmer T, Tilling K. Multivariate multilevel spline models for parallel growth processes: application to weight and mean arterial pressure in pregnancy. Stat Med 2012; 31: 3147-3164. 
Height/weight measurements from child records Obs $=28342$

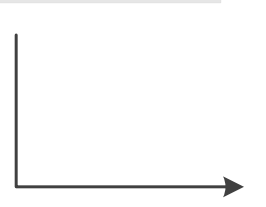

Height/weight measurements from T0 and T1 ( 8 centres) Obs $=29824$

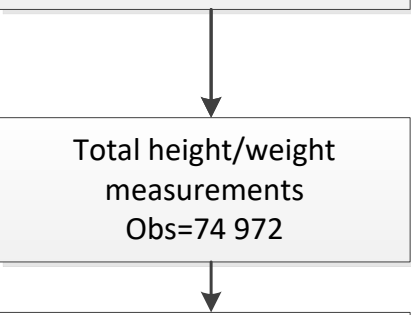

Height/weight from 6 centres with child records Obs=60 $647(\mathrm{~N}=12700)$

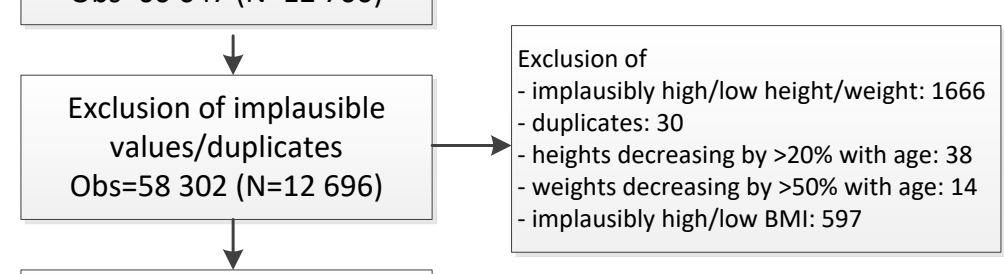

Minimum of 4 height/weight measurements per child Obs=36 $714(\mathrm{~N}=3436)$

Growth model (Step 1) Obs=29 418

( $N=3301 ;<6 y: 681, \geq 6 y: 2620$ )

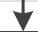

Information on all MetS components and growth (Step 2)

$\mathrm{N}=2264$

(<6y: 368, $\geq 6 y: 1896$ )

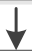

Information on all MetS components, covariates and growth (Step 2)

$\mathrm{N}=1381$

(<6y: 171, 26y: 1210) (measured or reported) Obs $=16806$

Exclusion of centres without early growth information

Missing information on delivery status Observations with small time lag

Fig. 1: Flow chart for number of children $(\mathrm{N})$ and $\mathrm{BMI}$ measurements (Obs) included in final study sample 
Sample with basic covariate information

Sample with full covariate information

\begin{tabular}{|c|c|c|c|c|c|c|c|c|c|c|c|c|}
\hline & \multicolumn{6}{|c|}{ Sample with basic covariate information } & \multicolumn{6}{|c|}{ Sample with full covariate information } \\
\hline & \multicolumn{2}{|c|}{$\begin{array}{c}<6 \text { years } \\
(\mathrm{N}=368 ; 16.3 \%)\end{array}$} & \multicolumn{2}{|c|}{$\begin{array}{c}\geq 6 \text { years } \\
(\mathrm{N}=1896 ; 83.7 \%)\end{array}$} & \multicolumn{2}{|c|}{$\begin{array}{c}\text { Total } \\
(\mathrm{N}=2264)\end{array}$} & \multicolumn{2}{|c|}{$\begin{array}{c}<6 \text { years } \\
(\mathrm{N}=171 ; 12.4 \%)\end{array}$} & \multicolumn{2}{|c|}{$\begin{array}{c}>=6 \text { years } \\
(\mathrm{N}=1210 ; 87.6 \%)\end{array}$} & \multicolumn{2}{|c|}{$\begin{array}{c}\text { Total } \\
(\mathrm{N}=1381)\end{array}$} \\
\hline & $\mathbf{N}$ & $\%$ & $\mathbf{N}$ & $\%$ & $\mathbf{N}$ & $\%$ & $\mathbf{N}$ & $\%$ & $\mathbf{N}$ & $\%$ & $\mathbf{N}$ & $\%$ \\
\hline Boys & 183 & 49.7 & 986 & 52.0 & 1,169 & 51.6 & 81 & 47.4 & 623 & 51.5 & 704 & 51.0 \\
\hline ISCED Level 0,1,2 & 49 & 13.5 & 262 & 13.9 & 311 & 13.8 & 12 & 7.0 & 131 & 10.8 & 143 & 10.4 \\
\hline ISCED Level 3,4 & 194 & 53.4 & 973 & 51.5 & 1,167 & 51.8 & 82 & 48.0 & 602 & 49.8 & 684 & 49.6 \\
\hline ISCED Level 5,6 & 120 & 33.1 & 656 & 34.7 & 776 & 34.4 & 77 & 45.0 & 476 & 39.4 & 553 & 40.1 \\
\hline Missing ISCED & 5 & - & 5 & - & 10 & - & 0 & - & 1 & - & 1 & - \\
\hline Full-term delivery & 237 & 64.4 & 1295 & 68.3 & 1,532 & 67.7 & 109 & 63.7 & 793 & 65.5 & 902 & 65.3 \\
\hline Pre-term delivery ( $\geq 1$ week) & 131 & 35.6 & 601 & 31.7 & 732 & 32.3 & 62 & 36.3 & 417 & 34.5 & 479 & 34.7 \\
\hline Italy & 63 & 17.1 & 188 & 9.9 & 251 & 11.1 & 22 & 12.9 & 98 & 8.1 & 120 & 8.7 \\
\hline Cyprus & 1 & 0.3 & 36 & 1.9 & 37 & 1.6 & 0 & 0.0 & 8 & 0.7 & 8 & 0.6 \\
\hline Belgium & 36 & 9.8 & 201 & 10.6 & 237 & 10.5 & 2 & 1.2 & 147 & 12.1 & 149 & 10.8 \\
\hline Germany & 166 & 45.1 & 847 & 44.7 & 1,013 & 44.7 & 63 & 36.8 & 460 & 38.0 & 523 & 37.9 \\
\hline Hungary & 4.0 & 1.1 & 178 & 9.4 & 182 & 8.0 & 3 & 1.8 & 117 & 9.7 & 120 & 8.7 \\
\hline Spain & 98 & 26.6 & 446 & 23.5 & 544 & 24 & 81 & 47.4 & 380 & 31.4 & 461 & 33.4 \\
\hline Thin at last measurement & 37 & 10.1 & 148 & 7.8 & 185 & 8.2 & 15 & 8.8 & 98 & 8.1 & 113 & 8.2 \\
\hline Overweight at last measurement & 38 & 10.3 & 325 & 17.1 & 363 & 16.0 & 15 & 8.8 & 212 & 17.5 & 227 & 16.4 \\
\hline \multirow[t]{2}{*}{ Obese at last measurement } & 13 & 3.5 & 116 & 6.1 & 129 & 5.7 & 6 & 3.5 & 77 & 6.4 & 83 & 6.0 \\
\hline & \multicolumn{2}{|c|}{$\begin{array}{c}\text { Mean } \\
(99 \% \mathrm{Cl})\end{array}$} & \multicolumn{2}{|c|}{$\begin{array}{c}\text { Mean } \\
(99 \% \mathrm{Cl})\end{array}$} & \multicolumn{2}{|c|}{$\begin{array}{c}\text { Mean } \\
(99 \% \mathrm{Cl})\end{array}$} & \multicolumn{2}{|c|}{$\begin{array}{c}\text { Mean } \\
(99 \% \mathrm{Cl})\end{array}$} & \multicolumn{2}{|c|}{$\begin{array}{c}\text { Mean } \\
(99 \% \mathrm{Cl})\end{array}$} & \multicolumn{2}{|c|}{$\begin{array}{c}\text { Mean } \\
(99 \% \mathrm{Cl})\end{array}$} \\
\hline MetS Score & \multicolumn{2}{|c|}{$\begin{array}{c}0.1 \\
(-0.3 ; 0.4)\end{array}$} & \multicolumn{2}{|c|}{$\begin{array}{c}0.5 \\
(0.4 ; 0.7)\end{array}$} & \multicolumn{2}{|c|}{$\begin{array}{c}0.4 \\
(0.3 ; 0.6)\end{array}$} & \multicolumn{2}{|c|}{$\begin{array}{c}-0.1 \\
(-0.5 ; 0.4)\end{array}$} & \multicolumn{2}{|c|}{$\begin{array}{c}0.5 \\
(0.3 ; 0.7)\end{array}$} & \multicolumn{2}{|c|}{$\begin{array}{c}0.5 \\
(0.3 ; 0.6)\end{array}$} \\
\hline Waist circumference (cm) & \multirow{3}{*}{\multicolumn{2}{|c|}{$\begin{array}{c}50.8 \\
(50.3 ; 51.4) \\
97.4 \\
(96.4 ; 98.4) \\
62.3 \\
(61.5 ; 63.1)\end{array}$}} & \multirow{2}{*}{\multicolumn{2}{|c|}{$\begin{array}{c}57.3 \\
(56.9 ; 57.8) \\
102.7 \\
(102.1 ; 103.2)\end{array}$}} & \multicolumn{2}{|c|}{$\begin{array}{c}56.3 \\
(55.9 ; 56.7)\end{array}$} & \multicolumn{2}{|c|}{$\begin{array}{c}51.0 \\
(50.2 ; 51.8)\end{array}$} & \multicolumn{2}{|c|}{$\begin{array}{c}57.6 \\
(56.9 ; 58.2)\end{array}$} & \multicolumn{2}{|c|}{$\begin{array}{c}56.7 \\
(56.2 ; 57.3)\end{array}$} \\
\hline Systolic blood pressure (mm Hg) & & & & & $\begin{array}{r}1 \\
(101 .\end{array}$ & $2.3)$ & $\begin{array}{r}9 \\
(96 .\end{array}$ & $9.6)$ & $(102$ & $3.6)$ & $(10$ & $03.0)$ \\
\hline Diastolic blood pressure (mm Hg) & & & $(63$ & & $\begin{array}{r}6 \\
(63 .\end{array}$ & & $\begin{array}{r}6 \\
(61 .\end{array}$ & $4.1)$ & & 1.9) & & $4.7)$ \\
\hline Triglycerides [mg/dL] & \multicolumn{2}{|c|}{$\begin{array}{c}58.8 \\
(55.6 ; 62.0)\end{array}$} & $(56$. & & $\begin{array}{r}5 \\
(56 .\end{array}$ & & $\begin{array}{r}5 \\
(52 .\end{array}$ & $1.1)$ & & .0) & & $8.8)$ \\
\hline Triglycerides [mmol/L] & & $7)$ & & & $(0$. & & $(0$. & & & & & \\
\hline
\end{tabular}




\begin{tabular}{|c|c|c|c|c|c|c|}
\hline $\begin{array}{l}\text { HDL cholesterol }[\mathrm{mg} / \mathrm{dL}] \\
\text { HDL cholesterol }[\mathrm{mmol} / \mathrm{L}] \\
\text { HOMA index* } \\
\text { Age at outcome assessment }\end{array}$ & $\begin{array}{c}49.1 \\
(47.3 ; 50.9) \\
1.3 \\
(1.2 ; 1.3) \\
0.9 \\
(0.7 ; 1.0) \\
5.1 \\
(5.0 ; 5.2) \\
\end{array}$ & $\begin{array}{c}54.6 \\
(53.7 ; 55.4) \\
1.4 \\
(1.4 ; 1.4) \\
1.3 \\
(1.2 ; 1.3) \\
8.5 \\
(8.4 ; 8.6)\end{array}$ & $\begin{array}{c}53.7 \\
(52.9 ; 54.5) \\
1.4 \\
(1.4 ; 1.4) \\
1.2 \\
(1.1 ; 1.2) \\
7.9 \\
(7.8 ; 8.0)\end{array}$ & $\begin{array}{c}50.3 \\
(47.6 ; 53.0) \\
1.3 \\
(1.2 ; 1.4) \\
0.8 \\
(0.6 ; 0.9) \\
5.2 \\
(5.1 ; 5.3)\end{array}$ & $\begin{array}{c}54.7 \\
(53.6 ; 55.7) \\
1.4 \\
(1.4 ; 1.4) \\
1.3 \\
(1.2 ; 1.3) \\
8.5 \\
(8.4 ; 8.6) \\
\end{array}$ & $\begin{array}{c}54.1 \\
(53.2 ; 55.1) \\
1.4 \\
(1.4 ; 1.4) \\
1.2 \\
(1.1 ; 1.3) \\
8.1 \\
(8.0 ; 8.2)\end{array}$ \\
\hline $\begin{array}{l}\text { Covariates } \\
\text { MVPA in minutes/day } \\
\text { Breast feeding duration [mth] } \\
\text { Fruits/vegetables [times/week] } \\
\text { Junk food [times/week] }\end{array}$ & & & & $\begin{array}{c}40.8 \\
(36.9 ; 44.8) \\
5.1 \\
(3.7 ; 6.4) \\
18.6 \\
(16.3 ; 20.9) \\
8.3 \\
(6.8 ; 9.8)\end{array}$ & $\begin{array}{c}44.8 \\
(43.1 ; 46.4) \\
5.2 \\
(4.7 ; 5.7) \\
18.3 \\
(17.4 ; 19.1) \\
10.1 \\
(9.4 ; 10.9)\end{array}$ & $\begin{array}{c}44.3 \\
(42.7 ; 45.8) \\
5.2 \\
(4.7 ; 5.6) \\
18.3 \\
(17.5 ; 19.1) \\
9.9 \\
(9.2 ; 10.6)\end{array}$ \\
\hline
\end{tabular}

Table 1: Description of the study population; means and $99 \%$ confidence intervals of covariates, metabolic risk score and its components by age group for the study population with basic (left; $\mathrm{N}=2264$ ) and complete covariate information (right; $\mathrm{N}=1381$ )

*HOMA was calculated as fasting insulin $(\mu \mathrm{U} / \mathrm{ml}) \times$ fasting glucose $(\mathrm{mmol} / \mathrm{l}) / 22.5$ 


\section{Blood pressure} z-score

$<6$ yrs $(\mathrm{N}=368)$

$\mathrm{BMl}$ at birth

BMl change 0-9 mths (S1)

$99 \% \mathrm{Cl}$

BMl change 9 mths - 6 yrs (S2)

Current BMI Z-score*

\section{$>=6$ yrs $(\mathrm{N}=1896)$}

$\mathrm{BMl}$ at birth

BMl change 0-9 mths (S1) 0.29

BMl change 9 mths - 6 yrs (S2) $\quad 1.78$

BMl change 6 to $<12$ yrs (S3) $\quad 1.06$

Current BMI z-score*

\section{Girls; < 6 yrs $(\mathrm{N}=185)$}

$\mathrm{BMI}$ at birth

BMl change 0-9 mths (S1)

BMl change 9 mths - 6 yrs (S2)

Current BMI z-score*

Girls; >= 6 yrs $(\mathrm{N}=910)$

$\mathrm{BMI}$ at birth

BMl change 0-9 mths (S1)

BMl change 9 mths - 6 yrs (S2) 1.92

BMl change 6 to $<12$ yrs (S3)

Current BMI z-score*

Boys; $<6$ yrs $(\mathrm{N}=183)$

$\mathrm{BMl}$ at birth

BMl change 0-9 mths (S1)

BMl change 9 mths - 6 yrs (S2)

Current BMI z-score*

Boys; >= 6 yrs $(\mathrm{N}=986)$

BMl at birth

BMl change 0-9 mths (S1)

BMl change 9 mths - 6 yrs (S2)

$\mathrm{BMl}$ change 6 to $<12$ yrs (S3)

Current BMI z-score*
$0.48 \quad(0.17 \cdot 0.79)$

$(0.46 ; 1.34)$

$(1.03 ; 1.64)$

$(1.07 ; 1.74)$

$(0.47 ; 0.78)$

$(0.05 ; 0.53)$

$(1.66 ; 1.90)$

$(0.88 ; 1.24)$

$(0.96 ; 1.38)$

$(0.09 ; 0.97)$

$(0.20 ; 1.44)$

$(0.81 ; 1.71)$

$(0.94 ; 1.93)$

$(0.37 ; 0.85)$

$(-0.26 ; 0.54)$

$(1.76 ; 2.09)$

$(0.61 ; 1.18)$

$(0.77 ; 1.49)$

$(-0.02 ; 0.90)$

$(0.33 ; 1.64)$

$(0.98 ; 1.83)$

$(0.93 ; 1.85)$

$(0.44 ; 0.83)$

$(0.13 ; 0.73)$

$(1.45 ; 1.79)$

$(0.95 ; 1.41)$

$(0.92 ; 1.47)$

\section{$\beta$}

$99 \% \mathrm{CI}$

$0.00 \quad(-0.12 ; 0.11)$

0.02

0.18

$(-0.15 ; 0.19)$

$(0.05 ; 0.31)$

$(0.05 ; 0.34)$

$(0.01 ; 0.11)$

$(0.02 ; 0.17)$

$(0.12 ; 0.22)$

$(0.10 ; 0.26)$

$(0.07 ; 0.27)$

$(-0.11 ; 0.19)$

$(-0.05 ; 0.30)$

$(-0.03 ; 0.36)$

$0.07 \quad(0.00 ; 0.15)$

$(-0.02 ; 0.22)$

$(0.11 ; 0.24)$

$(-0.02 ; 0.23)$

$(-0.09 ; 0.23)$

$(-0.22 ; 0.13)$

$(-0.16 ; 0.37)$

$(0.02 ; 0.43)$

$(0.01 ; 0.43)$

\section{$99 \% \mathrm{Cl}$}

$\beta$

$99 \% \mathrm{Cl}$

$(-0.02 ; 0.26)$

$(-0.01 ; 0.40)$

$(0.13 ; 0.45)$

$(0.11 ; 0.46)$

0.00

$-0.04$

$(-0.10 ; 0.09)$

$(-0.19 ; 0.10)$

$(-0.11 ; 0.12)$

$(-0.17 ; 0.08)$

$(-0.01 ; 0.12)$

$(-0.11 ; 0.08)$

$(0.37 ; 0.48)$

$(0.19 ; 0.38)$

$(0.13 ; 0.36)$

0.03

$(-0.01 ; 0.08)$

$(0.02 ; 0.15)$

$(0.11 ; 0.20)$

$(-0.03 ; 0.12)$

$(-0.13 ; 0.05)$

$(-0.17 ; 0.24)$

$(-0.04 ; 0.53)$

$(-0.10 ; 0.19)$

$(-0.26 ; 0.15)$

$(-0.15 ; 0.19)$

$(-0.19 ; 0.18)$

$(0.11 ; 0.62)$

$-0.01$

$(-0.05 ; 0.14)$

$(-0.24 ; 0.07)$

$(0.39 ; 0.55)$

$(0.13 ; 0.42)$

$(0.09 ; 0.46)$

0.02
0.07

$(-0.05 ; 0.09)$

$(-0.04 ; 0.18)$

$(0.13 ; 0.26)$

$(-0.09 ; 0.13)$

$(-0.22 ; 0.06)$

$(0.00 ; 0.41)$

$(-0.13 ; 0.48)$

$(0.03 ; 0.49)$

$(-0.02 ; 0.47)$

$-0.04$

$-0.04$

$(-0.18 ; 0.10)$

$(-0.25 ; 0.17)$

$(-0.17 ; 0.15)$

$(-0.23 ; 0.11)$

$(-0.01 ; 0.14)$

$(-0.09 ; 0.15)$

$(0.29 ; 0.45)$

$(0.17 ; 0.41)$

$(0.09 ; 0.37)$
$(0.09 ; 0.24) \quad 0.37$

$(0.13 ; 0.35) \quad 0.29$

$(0.11 ; 0.37) \quad 0.23$
$-0.06$

0.04

0.10

0.12

0.07

$-0.02$
$(-0.29 ; 0.14)$
$(-0.02 ; 0.10) \quad 0.48$

$(0.01 ; 0.19) \quad 0.19$

$(0.06 ; 0.19) \quad 0.96$

$(-0.03 ; 0.17) \quad 0.59$

$(-0.13 ; 0.10) \quad 0.74$
$99 \% \mathrm{Cl}$

$(0.21 ; 0.53)$

$(0.52 ; 0.94)$

(0.73; 0.99)

$(0.84 ; 1.10)$

$(0.40 ; 0.55)$

$(0.01 ; 0.25)$

$(0.97 ; 1.08)$

$(0.47 ; 0.63)$

$(0.70 ; 0.88)$

$(0.18 ; 0.64)$

$(0.40 ; 1.00)$

$(0.58 ; 0.98)$

$(0.70 ; 1.13)$

$(0.35 ; 0.59)$

$(-0.15 ; 0.25)$

$(1.01 ; 1.15)$

$(0.38 ; 0.62)$

$(0.72 ; 1.00)$

(0.09; 0.55)

$(0.44 ; 1.07)$

$(0.77 ; 1.09)$

$(0.84 ; 1.17)$

(0.38; 0.57$)$

$(0.04 ; 0.34)$

$(0.89 ; 1.04)$

$(0.49 ; 0.69)$

$(0.63 ; 0.86)$

Table 2: Associations (effect estimates and $99 \%$ confidence intervals) of BMI at birth, rates of BMI change during childhood and current BMI with the metabolic risk score and its single components estimated based on linear regression models (step 2) by age group and sex. Exposure variables (except current BMI z-score) were obtained from the linear-spline mixed-effects model (step 1). All models were adjusted for age, sex, country and previous periods of $\mathrm{BMI}$ change and BMI at birth. For current BMI z-score as exposure, the last period of change was not added to the model as the current BMI lies in this period. 
Exposure variables were standardised prior to analysis. The coefficients for BMI at birth and current BMI z-score represent the standard deviation change in the outcome associated with a one standard deviation increase in BMI at birth or current BMI z-score, respectively. The coefficients for BMI change in the different periods represent the standard deviation change in the outcome associated with a one standard deviation increase in the rate of BMI change in the specific period.

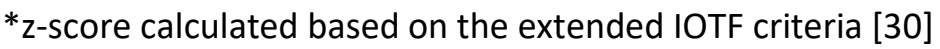

99\% Cl: $99 \%$ confidence interval 


\section{z-score}

0.38

0.14

$(0.04 ; 0.60)$

0.01

$(-0.19 ; 0.18)$

0.93

$(0.66 ; 1.04)$

$$
\mathrm{BMI} \text { at birth }
$$

BMl change 0-9 mths (S1) BMl change $9 \mathrm{mths}-6$ yrs (S2)

$\mathrm{BMI}$ change 6 to $<12 \mathrm{yrs}$ (S3) Current BMI z-score*

\begin{tabular}{llllllllll}
0.61 & $(0.46 ; 0.76)$ & 0.06 & $(0.01 ; 0.11)$ & 0.05 & $(-0.01 ; 0.11)$ & 0.03 & $(-0.01 ; 0.07)$ & 0.47 & $(0.39 ; 0.55)$ \\
0.31 & $(0.06 ; 0.57)$ & 0.10 & $(0.02 ; 0.18)$ & 0.00 & $(-0.10 ; 0.10)$ & 0.09 & $(0.01 ; 0.16)$ & 0.13 & $(0.00 ; 0.26)$ \\
1.72 & $(1.59 ; 1.85)$ & 0.16 & $(0.10 ; 0.21)$ & 0.40 & $(0.34 ; 0.47)$ & 0.14 & $(0.09 ; 0.19)$ & 1.02 & $(0.97 ; 1.08)$ \\
1.19 & $(0.96 ; 1.42)$ & 0.20 & $(0.09 ; 0.30)$ & 0.32 & $(0.21 ; 0.44)$ & 0.05 & $(-0.04 ; 0.15)$ & 0.61 & $(0.52 ; 0.71)$ \\
1.28 & $(1.00 ; 1.55)$ & 0.20 & $(0.07 ; 0.32)$ & 0.31 & $(0.17 ; 0.45)$ & -0.04 & $(-0.14 ; 0.07)$ & 0.81 & $(0.70 ; 0.92)$ \\
\hline
\end{tabular}

Table 3: Associations (effect estimates and 99\% confidence intervals) of BMI at birth, rates of BMl change during childhood and current BMI with the metabolic risk score and its single components estimated based on linear regression models (step 2) by age group. Exposure variables (except current BMI zscore) were obtained from the linear-spline mixed-effects model (step 1). All models were adjusted for age, sex, country, maximum ISCED level of parents, previous periods of BMI change and BMI at birth. For current BMI z-score as exposure the last period of change was not added as covariate to the model as the current BMI lies in this period. Breast feeding duration, junk food frequency, fruit/veg frequency, minutes per day spent in moderate-to-vigorous physical activity and current height (for blood pressure as outcome only) were added if occurring at the same time or prior to the exposure.

Exposure variables were standardised prior to analysis. The coefficients for BMI at birth and current BMI z-score represent the standard deviation change in the outcome associated with a one standard deviation increase in BMI at birth or current BMI z-score, respectively. The coefficients for BMI change in the different periods represent the standard deviation change in the outcome associated with a one standard deviation increase in the rate of BMI change in the specific period.

*z-score calculated based on the extended IOTF criteria [30]

99\% Cl: $99 \%$ confidence interval 
Supplementary material A1: Börnhorst et al. Associations between early body mass index trajectories and later metabolic risk factors in European children: The IDEFICS Study. European Journal of Epidemiology (Correspondence: Claudia Börnhorst, Leibniz-Institute for Prevention Research and Epidemiology - BIPS, Bremen, Germany; email: boern@bips.uni-bremen.de)

\begin{tabular}{|c|c|c|c|c|c|c|c|c|c|}
\hline \multirow{2}{*}{ Country } & \multirow{2}{*}{$\begin{array}{l}\text { Total number } \\
\text { of children }\end{array}$} & \multicolumn{7}{|c|}{ Children with $4,5, \ldots, \geq 10 \mathrm{BMI}$ measurements } & \multirow{2}{*}{$\begin{array}{l}\text { Total number of } \\
\text { measurements }\end{array}$} \\
\hline & & 4 & 5 & 6 & 7 & 8 & 9 & $\geq 10$ & \\
\hline Italy & 347 & 140 & 164 & 43 & 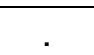 & . & . & 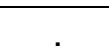 & 1630 \\
\hline Cyprus & 73 & 1 & 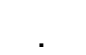 & 4 & 1 & 4 & 6 & 57 & 801 \\
\hline Belgium & 422 & 2 & 7 & 12 & 37 & 80 & 91 & 193 & 3950 \\
\hline Germany & 1534 & 36 & 58 & 118 & 199 & 351 & 417 & 355 & 12731 \\
\hline Hungary & 240 & 10 & 11 & 7 & 8 & 29 & 39 & 136 & 2407 \\
\hline Spain & 685 & 7 & 10 & 14 & 26 & 43 & 63 & 522 & 7899 \\
\hline Total & 3301 & 196 & 250 & 198 & 271 & 507 & 616 & 1263 & 29418 \\
\hline
\end{tabular}

Table A1: Numbers of children and numbers of available BMI measurements during childhood by country (used in the growth model; step 1) 
Supplementary material A2: Börnhorst et al. Associations between early body mass index trajectories and later metabolic risk factors in European children: The IDEFICS Study. European Journal of Epidemiology (Correspondence: Claudia Börnhorst, Leibniz-Institute for Prevention Research and Epidemiology - BIPS, Bremen, Germany; email: boern@bips.uni-bremen.de)

\section{Description of the linear-spline growth model}

The general growth model was defined as follows:

$$
\begin{aligned}
B M I_{i, j}=\left(\beta_{0}\right. & \left.+u_{i, 0}+\varepsilon_{i, j}\right)+\left(\beta_{1}+u_{i, 1}\right) S 1_{i, j}+\left(\beta_{2}+u_{i, 2}\right) S 2_{i, j}+\left(\beta_{3}+u_{i, 3}\right) S 3_{i, j}+\beta_{4}\left(\text { boy }_{i}\right) \\
& \left.+\beta_{5}\left(\text { boy }_{i}\right) S 1_{i, j}+\beta_{6}\left(\text { boy }_{i}\right) S 2_{i, j}+\beta_{7}\left(\text { boy }_{i}\right) S 3_{i, j}+\beta_{8}\left(\text { preterm }_{i}\right)+\beta_{9} \text { (preterm }_{i}\right) S 1_{i, j}+\beta_{10}\left(\text { preterm }_{i}\right) S 2_{i, j}+\beta_{11}\left(\text { preterm }_{i}\right) S 3_{i, j} \\
& +\beta_{12}\left(\text { source }_{i, j}\right)
\end{aligned}
$$

where $B M I_{i, j}$ denotes the $j$ 's BMI measurement of child $i$, the fixed coefficient $\beta_{0}$ describes the average intercept for girls delivered full-term, $\beta_{1}$ is the average predicted linear change (slope) in BMI per year for the first period (S1=0 to $9 \mathrm{mths}$ ), $\beta_{2}$ the average linear change for the second

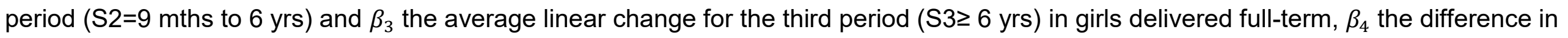
average intercept between boys and girls, $\beta_{5}, \beta_{6}$ and $\beta_{7}$ denote the difference in average slopes between boys and girls, $\beta_{8}$ the difference in average intercept between full-term and pre-term delivered children, $\beta_{9}, \beta_{10}$ and $\beta_{11}$ denote the differences in average linear slopes between fullterm and pre-term delivered children, and $\beta_{12}$ describes the average difference in intercept between self-reported and routinely measured birth weights/heights.

The random coefficients $u_{i, k}, k=1,2,3$, indicate the deviation of individual $i$ from the average slope between knot points $k-1$ and $k$ and $u_{i 0}$ describes the deviation of individual i's intercept from the average intercept.

An unstructured covariance matrix was modelled for the random effects. This means that variances/covariances could take the value that the data demand. The model further accounts for changes in variances of BMI during childhood by defining heterogeneity by age group in the covariance structure of the measurement errors. 
Supplementary material A3: Börnhorst et al. Associations between early body mass index trajectories and later metabolic risk factors in European children: The IDEFICS Study. European Journal of Epidemiology (Correspondence: Claudia Börnhorst, Leibniz-Institute for Prevention Research and Epidemiology - BIPS, Bremen, Germany; email: boern@bips.uni-bremen.de)

Table A3 shows the results of the BMI growth model (step 1), i.e. estimates of mean BMI at birth and growth velocities in the different periods by age group and sex. The table further includes sample mean values of current BMI and BMI z-scores as well as the mean ages at last measurement. Estimated BMl at birth as well as growth velocity between 0 to 9 mths (S1) was slightly lower in girls compared to boys. As expected, the growth velocity between $9 \mathrm{mths}$ and 6 yrs (S2) was negative (age before adiposity rebound), where the decrease was higher in boys compared to girls. In the third period ( $\geq 6 \mathrm{yrs}$ ), the BMI velocity was again positive and almost equal for boys and girls.

\begin{tabular}{|c|c|c|c|c|c|c|c|c|}
\hline \multirow[b]{3}{*}{ Growth velocity of BMI (model estimates) } & \multicolumn{4}{|c|}{$<6$ years } & \multicolumn{4}{|c|}{$>=6$ years } \\
\hline & \multicolumn{2}{|c|}{ Girls } & \multicolumn{2}{|c|}{ Boys } & \multicolumn{2}{|c|}{ Girls } & \multicolumn{2}{|c|}{ Boys } \\
\hline & Mean & SE & Mean & SE & Mean & SE & Mean & SE \\
\hline BMl at birth $\left(\mathrm{kg} / \mathrm{m}^{2}\right)$ & 13.97 & 0.080 & 14.14 & 0.077 & 13.88 & 0.040 & 14.23 & 0.039 \\
\hline Velocity 0 to 9 mths $\left(\mathrm{kg} / \mathrm{m}^{2}\right.$ per $\left.\mathrm{yr}\right)(\mathrm{S} 1)$ & 3.88 & 0.150 & 4.21 & 0.145 & 4.07 & 0.078 & 4.18 & 0.076 \\
\hline Velocity $9 \mathrm{mths}$ to $6 \mathrm{yrs}\left(\mathrm{kg} / \mathrm{m}^{2}\right.$ per $\left.\mathrm{yr}\right)(\mathrm{S} 2)$ & -0.26 & 0.026 & -0.35 & 0.025 & -0.25 & 0.013 & -0.34 & 0.013 \\
\hline Velocity 6 to $<12$ yrs $\left(\mathrm{kg} / \mathrm{m}^{2}\right.$ per $\left.\mathrm{yr}\right)(\mathrm{S} 3)$ & & & & & 0.67 & 0.022 & 0.66 & 0.021 \\
\hline Current status (sample estimates) & Mean & SD & Mean & SD & Mean & SD & Mean & SD \\
\hline Current BMI & 15.91 & 1.58 & 15.79 & 1.51 & 17.31 & 3.00 & 17.16 & 2.81 \\
\hline Current BMI z-score & 0.32 & 0.99 & 0.13 & 1.04 & 0.49 & 1.08 & 0.42 & 1.09 \\
\hline Age at last BMI measurement & 5.12 & 0.67 & 5.09 & 0.68 & 8.50 & 1.34 & 8.45 & 1.40 \\
\hline
\end{tabular}

Table A3: BMI at birth and BMI velocities until 12 years of age from linear-spline mixed-effects models; sample mean of current BMI and BMI z-score according to extended IOTF criteria ${ }^{30}$ 
Supplementary material A4: Börnhorst et al. Associations between early body mass index trajectories and later metabolic risk factors in European children: The IDEFICS Study.

European Journal of Epidemiology (Correspondence: Claudia Börnhorst, Leibniz-Institute for Prevention Research and Epidemiology - BIPS, Bremen, Germany; email: boern@bips.unibremen.de)

Table A4 displays the correlations between the random intercepts (BMI at birth) and slopes (rates of BMI change in S1, S2 and S3) estimated by the linear-spline mixedeffects model stratified by age group. Negative correlations were observed for BMI at birth with rate of BMI change in S2 and for BMl change in period S1 with rate of BMI change in S2. BMI at birth and change in S3 as well as BMI changes in S2 and S3 were positively correlated.

\begin{tabular}{l|ccc} 
& Estimate & SE & p-value \\
\hline$<6 y$ & & & \\
Variance(BMI at birth) & 0.50 & 0.09 & $<.0001$ \\
Covariance(BMI at birth, S1) & 0.13 & 0.14 & 0.345 \\
Variance(S1) & 2.32 & 0.33 & $<.0001$ \\
Covariance(BMl at birth, S2) & -0.07 & 0.02 & 0.000 \\
Covariance (S1, S2) & -0.17 & 0.04 & $<.0001$ \\
Variance(S2) & 0.10 & 0.01 & $<.0001$ \\
\hline 6 years & & & \\
Variance(BMI at birth) & 0.34 & 0.05 & $<.0001$ \\
Covariance(BMl at birth, S1) & 0.14 & 0.08 & 0.072 \\
Variance(S1) & 2.15 & 0.18 & $<.0001$ \\
Covariance(BMl at birth, S2) & -0.03 & 0.01 & 0.008 \\
Covariance(S1, S2) & -0.12 & 0.02 & $<.0001$ \\
Variance(S2) & 0.12 & 0.00 & $<.0001$ \\
Covariance(BMl at birth, S3) & 0.05 & 0.02 & 0.006 \\
Covariance(S1, S3) & 0.02 & 0.04 & 0.614 \\
Covariance(S2, S3) & 0.06 & 0.01 & $<.0001$ \\
Variance(S3) & 0.20 & 0.01 & $<.0001$
\end{tabular}

Table A4: Variances and covariances of random effects estimated in course of the linearspline growth models (step 1) stratified by age group

BMI at birth: Random intercept for body mass index

S1: Random slope for body mass index between 0 and 9 mths

S2: Random slope for body mass index between 9 mths and 6 yrs

S3: Random slope for body mass index between 6 and $<12$ yrs 
Supplementary material A5: Börnhorst et al. Associations between early body mass index trajectories and later metabolic risk factors in European children: The IDEFICS Study. European Journal of Epidemiology (Correspondence: Claudia Börnhorst, Leibniz-Institute for Prevention Research and Epidemiology - BIPS, Bremen, Germany; email: boern@bips.uni-bremen.de)

\begin{tabular}{|c|c|c|c|c|c|c|c|c|c|c|}
\hline & \multicolumn{2}{|c|}{ MetS score } & \multicolumn{2}{|c|}{$\begin{array}{c}\text { Blood pressure } \\
\text { z-score }\end{array}$} & \multicolumn{2}{|c|}{ HOMA z-score } & \multicolumn{2}{|c|}{ LIPIDS z-score } & \multicolumn{2}{|c|}{ Waist z-score } \\
\hline & $\beta$ & $99 \% \mathrm{Cl}$ & $\beta$ & $99 \% \mathrm{Cl}$ & $\beta$ & $99 \% \mathrm{Cl}$ & $\beta$ & $99 \% \mathrm{Cl}$ & $\beta$ & $99 \% \mathrm{Cl}$ \\
\hline \multicolumn{11}{|l|}{$\begin{array}{l}\text { Full-term delivery } \\
<6 \text { yrs }(\mathrm{N}=237)\end{array}$} \\
\hline BMI at birth & 0.43 & $(0.03 ; 0.84)$ & -0.02 & $(-0.16 ; 0.13)$ & 0.10 & $(-0.09 ; 0.28)$ & 0.00 & $(-0.13 ; 0.12)$ & 0.36 & $(0.15 ; 0.57)$ \\
\hline BMI change 0-9 mths (S1) & 1.22 & $(0.67 ; 1.78)$ & 0.09 & $(-0.12 ; 0.31)$ & 0.37 & $(0.11 ; 0.63)$ & -0.03 & $(-0.22 ; 0.15)$ & 0.80 & $(0.52 ; 1.07)$ \\
\hline BMI change 9 mths - 6 yrs (S2) & 1.34 & $(0.96 ; 1.71)$ & 0.11 & $(-0.06 ; 0.28)$ & 0.31 & $(0.12 ; 0.51)$ & 0.00 & $(-0.15 ; 0.14)$ & 0.92 & $(0.77 ; 1.07)$ \\
\hline Current BMI z-score* & 1.33 & $(0.93 ; 1.74)$ & 0.11 & $(-0.07 ; 0.29)$ & 0.30 & $(0.09 ; 0.52)$ & -0.07 & $(-0.22 ; 0.09)$ & 0.99 & $(0.83 ; 1.14)$ \\
\hline \multicolumn{11}{|l|}{$>=6$ yrs $(\mathrm{N}=1295)$} \\
\hline BMl at birth & 0.66 & $(0.47 ; 0.84)$ & 0.08 & $(0.02 ; 0.14)$ & 0.07 & $(-0.01 ; 0.14)$ & 0.04 & $(-0.01 ; 0.10)$ & 0.47 & $(0.37 ; 0.56)$ \\
\hline BMI change 0-9 mths (S1) & 0.28 & $(-0.01 ; 0.58)$ & 0.08 & $(-0.01 ; 0.18)$ & -0.02 & $(-0.13 ; 0.10)$ & 0.08 & $(0.00 ; 0.16)$ & 0.13 & $(-0.01 ; 0.28)$ \\
\hline BMI change 9 mths - 6 yrs (S2) & 1.75 & $(1.61 ; 1.89)$ & 0.15 & $(0.09 ; 0.21)$ & 0.44 & $(0.37 ; 0.50)$ & 0.14 & $(0.09 ; 0.20)$ & 1.02 & $(0.96 ; 1.08)$ \\
\hline BMI change 6 to $<12$ yrs (S3) & 1.11 & $(0.89 ; 1.33)$ & 0.20 & $(0.10 ; 0.30)$ & 0.29 & $(0.18 ; 0.41)$ & 0.06 & $(-0.03 ; 0.15)$ & 0.55 & $(0.46 ; 0.65)$ \\
\hline Current BMI Z-score* & 1.15 & $(0.89 ; 1.42)$ & 0.17 & $(0.05 ; 0.29)$ & 0.23 & $(0.10 ; 0.37)$ & -0.04 & $(-0.14 ; 0.07)$ & 0.79 & $(0.69 ; 0.89)$ \\
\hline \multicolumn{11}{|l|}{$\begin{array}{l}\text { Pre-term delivery } \\
<6 \text { yrs }(\mathrm{N}=131)\end{array}$} \\
\hline BMI at birth & 0.51 & $(0.01 ; 1.00)$ & 0.01 & $(-0.17 ; 0.19)$ & 0.15 & $(-0.09 ; 0.38)$ & -0.01 & $(-0.17 ; 0.16)$ & 0.36 & $(0.10 ; 0.61)$ \\
\hline BMI change 0-9 mths (S1) & 0.52 & $(-0.21 ; 1.26)$ & -0.10 & $(-0.38 ; 0.18)$ & -0.07 & $(-0.43 ; 0.28)$ & -0.04 & $(-0.29 ; 0.21)$ & 0.74 & $(0.40 ; 1.09)$ \\
\hline BMI change 9 mths - 6 yrs (S2) & 1.20 & $(0.65 ; 1.74)$ & 0.30 & $(0.08 ; 0.52)$ & 0.18 & $(-0.11 ; 0.48)$ & -0.03 & $(-0.24 ; 0.17)$ & 0.74 & $(0.51 ; 0.98)$ \\
\hline Current BMI z-score* & 1.39 & $(0.77 ; 2.02)$ & 0.33 & $(0.07 ; 0.58)$ & 0.23 & $(-0.11 ; 0.56)$ & -0.04 & $(-0.28 ; 0.20)$ & 0.88 & $(0.62 ; 1.14)$ \\
\hline \multicolumn{11}{|l|}{$>=6$ yrs $(\mathrm{N}=601)$} \\
\hline BMI at birth & 0.55 & $(0.28 ; 0.82)$ & 0.03 & $(-0.06 ; 0.12)$ & 0.03 & $(-0.07 ; 0.14)$ & 0.00 & $(-0.08 ; 0.08)$ & 0.49 & $(0.35 ; 0.62)$ \\
\hline BMI change 0-9 mths (S1) & 0.31 & $(-0.12 ; 0.74)$ & 0.12 & $(-0.02 ; 0.27)$ & -0.02 & $(-0.19 ; 0.15)$ & 0.08 & $(-0.05 ; 0.21)$ & 0.12 & $(-0.10 ; 0.34)$ \\
\hline BMI change 9 mths - 6 yrs (S2) & 1.88 & $(1.66 ; 2.11)$ & 0.22 & $(0.12 ; 0.32)$ & 0.41 & $(0.30 ; 0.52)$ & 0.20 & $(0.11 ; 0.29)$ & 1.06 & $(0.96 ; 1.16)$ \\
\hline BMI change 6 to $<12$ yrs (S3) & 1.00 & $(0.68 ; 1.32)$ & 0.13 & $(-0.02 ; 0.28)$ & 0.28 & $(0.12 ; 0.44)$ & 0.03 & $(-0.11 ; 0.16)$ & 0.56 & $(0.42 ; 0.70)$ \\
\hline Current BMI z-score* & 1.19 & $(0.79 ; 1.59)$ & 0.18 & $(0.00 ; 0.37)$ & 0.26 & $(0.06 ; 0.46)$ & -0.05 & $(-0.21 ; 0.12)$ & 0.79 & $(0.61 ; 0.96)$ \\
\hline
\end{tabular}

Table A5: Effect estimates (and 99\% confidence intervals) of BMI at birth, changes of BMI during childhood and current BMI on the metabolic risk score and its single components estimated based on a linear regression (step 2) by age group and by in-time vs. per-term delivery. Exposures (except current BMl zscore) were obtained from the linear spline model (step 1). All models were adjusted for age, sex, country and previous periods of BMl change and BMI at birth; blood pressure models were additionally adjusted for height. When regarding current BMI z-score as exposure the last period of change was not added to the model as the current BMI lies in this period.

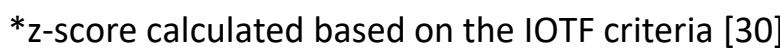
99\% Cl: $99 \%$ confidence interval 